\title{
Pengaruh Lingkungan Kerja, Stress Kerja, Dan Konflik Kerja Terhadap Kinerja Karyawan Pt. Trunojoyo Sumber Listrindo
}

\author{
${ }^{1}$ Hendrian Yonata, ${ }^{2}$ Sugandha \\ 1STAB Dharma Widya \\ ${ }^{2}$ Universitas Buddhi Dharma
}

\author{
Alamat Surat \\ Email: hendrian@stabdharmawidya.ac.id \\ suganda.suganda@ubd.ac.id
}

Article History:

Diajukan: 30-03-2021; Direvisi: 14-04-2021; Diterima: 28-04-2021

\begin{abstract}
ABSTRAK
Tujuan dari penelitian ini adalah untuk mengetahui Lingkungan Kerja, Stress Kerja Dan Konflik Kerja secara secara parsial (sendiri-sendiri) maupun simultan (bersama-sama) terhadap Kinerja Karyawan pada PT Trunojoyo Sumber Listrindo, Penelitian dilakukan dengan menyebar kuensioner, sedang metode penelitian dengan menggunakan Simple Random Sampling. Variabel independen dalam penelitian ini adalah Lingkungan Kerja, Stress Kerja, dan Konflik Kerja sedangkan variabel dependen dalam penelitian ini adalah Kinerja. Metode pengumpulan data digunakan dengan cara menyebarkan kuesioner secara langsung kepada Karyawan PT Trunojoyo Sumber Listrindo. Metode analisis yang digunakan dalm penelitian ini menggunakan analisis koefisien determinasi, analisis regresi berganda uji $\mathrm{F}$ serta uji $\mathrm{t}$, dengan menggunakan SPSS Versi 25.00 yang didasarkan pada data dari 100 karyawan PT Trunojoyo Sumber Listrindo. Uji t menunjukkan bahwa besarnya $t$ hitung untuk lingkungan kerja adalah 7.420, nilai $t$ hitung untuk stress kerja sebesar 6.604, dan nilai t hitung untuk konflik kerja sebesar 3.778 yang semuanya menunjukkan lebih besar dari t tabel 1.966, sehingga hipotesis ini menyatakan bahwa lingkungan kerja, stress kerja, dan konflik kerja berpengaruh positif secara parsial terhadap Kinerja Karyawan pada PT Trunojoyo Sumber Listrindo Dari hasil uji F diperoleh hasil untuk Nilai $F$ hitung sebesar 221.640 dengan nilai signifikansi sebesar 0.000 sehingga nilai $F$ hitung $>F_{\text {tabel }}$ atau $221.640>3.09$ atau tingkat signifikasi (sig) $0.000<0.05$, sehingga keputusannya menolak Ho dan menerima Ha. Hal ini berarti secara simultan (bersama-sama) variabel bebas (lingkungan kerja, stress kerja dan konflik kerja) mempengaruhi terhadap Kinerja Karyawan pada PT. Trunojoyo Sumber Listrindo dan nilai adjusted $R^{2}$ dalam penelitian ini hasil koefisien determinasi menunjukkan bahwa lingkungan kerja, stress kerja dan konflik kerja memberikan sumbangan sebesar $80.7 \%$ terhadap kinerja Karyawan pada PT.Trunojoyo Sumber Listrindo.
\end{abstract}

Kata Kunci: Lingkungan kerja; stress kerja; konflik kerja; kinerja 


\section{ABSTRACT}

The purpose of this study was to determine the Work Environment, Work Stress and Work Conflict partially (individually) or simultaneously (jointly) on Employee Performance at PT Trunojoyo Sumber Listrindo. Simple Random Sampling. The independent variable in this study is the work environment, work stress, and work conflict, while the dependent variable in this study is performance. The data collection method is used by distributing questionnaires directly to employees of PT Trunojoyo Sumber Listrindo. The analytical method used in this study uses the coefficient of determination analysis, multiple regression analysis of the $F$ test and the $t$ test, using SPSS Version 25.00 which is based on data from 100 employees of PT Trunojoyo Sumber Listrindo. The t test shows that the $t$ value for the work environment is 7,420, the $t$ value for work stress is 6,604, and the $t$ value for work conflict is 3,778, all of which show greater than table 1,966, so this hypothesis states that the work environment, stress Work, and work conflict have a partially positive effect on Employee Performance at PT Trunojoyo Sumber Listrindo.From the results of the $F$ test, the results obtained for the calculated $F$ value of 221,640 with a significance value of 0.000 so that the value of $F$ count $>F$ table or 221,640>3.09 or the level of significance (sig ) $0.000<0.05$, so the decision to reject Ho and accept Ha. This means that simultaneously (together) the independent variables (work environment, work stress and work conflict) affect the performance of employees at PT. Trunojoyo Sumber Listrindo and the adjusted R2 value in this study the results of the coefficient of determination show that the work environment, work stress and work conflict contribute $80.7 \%$ to the performance of employees at PT. Trunojoyo Sumber Listrindo.

\section{Keywords: Work environment; work stress; work conflict; performance}

\section{PENDAHULUAN}

Suatu perusahaan dalam melakukan kegiatan usahanya akan berusaha untuk mencapai tujuan perusahaan yang sebelumnya sudah ditetapkan. Hal tersebut tentu saja menjadi perhatian yang harus dilakukan suatu perusahaan baik perusahaan nasional maupun perusahaan bertaraf internasional dengan menerapkan efisiensi, efektifitas, dan produktifitas. Hal ini dilakukan perusahaan agar dapat bersaing dengan kompetitor bisnis yang lain, serta agar mengikuti perkembangan zaman dan juga pengetahuan teknologi yang semakin pesat. Tentu saja perusahaan sudah seharusnya memberikan perhatian kepada sumber daya manusianya sehingga dapat menciptakan semangat kerja yang tinggi, yang akhirnya dapat memberikan suatu produktivitas dan juga keberhasilan suatu perusahaan dalam mencapai tujuannya. Semakin baik kualitas yang diberikan dari karyawan dalam suatu perusahaan maka semakin tinggi juga daya saing diantara perusahaan-perusahaan besar yang ada.

Keberhasilan yang diraih suatu perusahaan tentu saja hasil kerja keras yang yang diberikan individu karyawannya. Tidak dapat dipungkiri karyawan dalam suatu perusahaan merupakan aset yang sangat berharga dan perlu diperhatikan serta dibina dan juga diarahkan dengan baik, sehingga perusahaan dapat menghasilkan karyawan yang memiliki kompetensi dan juga memiliki prestasi. Oleh karena itu mempunyai kinerja yang baik adalah keinginan yang diharapkan dari setiap organisasi ataupun perusahaan, jika adanya proforma kinerja yang baik maka akan tercipta hubungan yang baik, harmonis dan juga dapat memberikan suasana kerja yang baik serta menyenangkan. Sehingga karyawan perusahaan akan selalu berusaha mewujudkan tujuan perusahaan, dan juga dapat membantu perusahaan untuk mencapai visi dan misi serta mencapai tujuan yang sudah ditetapkan sebelumnya. 
Proses kegiatan suatu perusahaan yang dilakukan sehari-hari tentunya membuat karyawan mengalami naik turunnya kinerja yang diberikan oleh karyawan tersebut dalam menjalankan aktifitasnya didalam perusahaan. Hal ini berarti menunjukan adanya hubungan positif yang kuat antara karyawan dan perusahaan tempat dimana karyawan bekerja. Maka dalam hal ini perusahaan perlu mengembangkan cara untuk dapat mempertahankan karyawan serta tetap menjaga kinerja karyawan tersebut, agar karyawan dapat terus memberikan kontribusi yang maksimal kepada perusahaan.

Salah satu yang perlu dilakukan perusahaan agar karyawan dapat memberikan kinerja yang maksimal adalah menyediakan lingkungan kerja yang tentram, nyaman dan damai agar karyawan dapat memberikan kinerja yang terbaik untuk perusahaan.

Lingkungan kerja merupakan sarana yang ada didalam suatu organisasi atau suatu perusahaan baik lingkungan fisik, lingkungan sosial, maupun lingkungan virtual yang digunakan untuk meningkatkan kinerja karyawan dan kinerja perusahaan yang secara berkesinambungan.

Lingkungan kerja juga merupakan tempat yang digunakan sebagai wadah organisasi berada dan dimana seluruh karyawan dapat melakukan, melaksanakan tugas dan juga tanggung jawab yang diberikan. Selain itu karyawan dapat melaksanakan tanggung jawab pekerjaannya dengan berbagai sarana dan prasarana yang sudah disiapkan juga menunjang karyawan tersebut, agar tercapai visi dan misi yang sudah ditetapkan.

Dalam suatu perusahaan atau suatu organisasi lingkungan kerja bukan saja masalah sarana dan prasarana yang dipenuhi oleh perusahaan. Namun lingkungan kerja juga harus dapat memperhatikan hubungan yang terjalin diantara rekan sekerja dan juga hubungan yang terjalin antara karyawan dengan atasannya. Interaksi yang dilakukan dengan baik dan mudah dipahami antara atasan dan karyawan perlu dibangun didalam suatu perusahaan agar menciptakan lingkungan kerja yang baik, dan rukun. Sehingga karyawan dapat memberikan performa yang maksimal dalam mengerjakan pekerjaan yang diberikan perusahaan.

Selain lingkungan kerja, perusahaan juga perlu memperhatikan stress kerja yang dialami oleh karyawan. Stress kerja merupakan kondisi dimana perasaan tertekan yang dialami karyawan dalam menghadapi atau melakukan suatu pekerjaan. Stress kerja ini tampak dari Simptom, antara lain emosi tidak stabil, perasaan tidak tenang, suka menyendiri, sulit tidur, tidak bisa rileks, cemas, tegang, gugup, tekanan darah meningkat, dan mengalami gangguan pencernaan.

Stress kerja juga memiliki dampak negatif terhadap keadaan psikologis dan biologis yang mungkin akan dialami oleh setiap karyawan. Sebagai karyawan kita tidak dapat menghindari bahwa adanya tuntutan pekerjaan serta tanggung jawab yang diberikan perusahaan kepada kita, akan memberikan beban kerja karyawan seperti kebutuhan untuk dapat bekerja keras, cepat, dan tepat. Dan juga jumlah pekerjaan yang terus bertambah setiap harinya serta waktu yang terbatas tentu saja akan menimbulkan stress kerja.

Stress kerja yang seringkali dialami oleh karyawan akibat lingkungan kerja yang dihadapi karyawan tentu saja akan mempengaruhi kinerja yang diberikan oleh karyawannya. Selain itu tekanan yang didapat dari rekan sekerja dan juga atasan akan sangat mempengaruhi stress kerja dari karyawan itu sendiri.

Salah satu hal penting lainnya yang perlu juga diperhatikan oleh suatu perusahaan selain dari lingkungan kerja dan stress kerja adalah konflik kerja. Konflik kerja adalah proses komunikasi yang dilakukan oleh antara dua orang atau lebih yang berusaha menyingkirkan pihak lain dengan cara menghancurkan salah satu pihak dengan menentang tujuan dari salah satu pihak. Atau bisa dikatakan juga bahwa konflik adalah perselisihan yang sering kali terjadi dan dinilai sangat merugikan didalam suatu organisasi atau perusahaan. Konflik juga biasanya 
dilatarbelakangi oleh perbedaan cara berpikir, tingkah laku, dan sikap dari satu individu dengan individu lainnya. Dalam kehidupan sehari-hari yang dijalani karyawan dalam suatu perusahaan konflik kerja adalah salah satu proses sosial yang tidak dapat dihindari karyawan.

Perbedaan pendapat yang sering kali terjadi didakam suatu organisasi akan menimbulkan konflik yang akan berakhir dengan munculnya ketidakcocokan yang timbul antara satu sama lain, dan akhirnya membuat masing-masing individu akan merasa tidak nyaman berada disekitar individu tersebut. Dan mengakitbatkan individu tersebut akan mencari kebenarannya sendiri dan menyalahkan individu yang lain. Selain dari masalah ketidakcocokan antara satu sama lain, komunikasi tidak sehat yang terjadi didalam kehidupan pekerjaan seharihari akan mempengaruhi kesalahpahaman dan berujung menimbulkan konflik baik secara langung maupun secara tidak langung yang akan berpengaruh kepada setiap kinerja karyawan.

Lingkungan kerja, stress kerja, dan konflik kerja sangat berkaitan satu sama lain dan dapat berujung kepada kinerja karyawan, yang kebanyakan dari mereka tidak menyadari hal itu sering terjadi didalam kehidupan lingkungan kerja. Dan tentu saja perusahaan tidak bisa mengabaikan dan perlu memperhatikan hal tersebut agar dapat menciptakan lingkungan kerja yang tentram, nyaman, dan juga damai agar kinerja karyawan meningkat.

Berdasarkan uraian di atas peneliti melakukan penelitian dengan judul "PENGARUH LINGKUNGAN KERJA, STRESS KERJA, DAN KONFLIK KERJA TERHADAP KINERJA KARYAWAN PT. TRUNOJOYO SUMBER LISTRINDO”.

\subsection{Rumusan Masalah}

Sesuai dengan identifikasi masalah yang telah dijabarkan diatas, maka rumusan masalah dalam penelitian ini sebagai berikut:

1. Seberapa besar pengaruh lingkungan terhadap kinerja karyawan di PT. Trunojoyo Sumber Listrindo?

2. Seberapa besar pengaruh stress kerja terhadap kinerja karyawan di PT. Trunojoyo Sumber Listrindo?

3. Seberapa besar pengaruh konflik kerja berpengaruh terhadap kinerja karyawan di PT. Trunojoyo Sumber Listrindo?

4. Seberapa besar pengaruh lingkungan kerja, stress kerja, dan konflik kerja terhadap kinerja karyawan di PT. Trunojoyo Sumber Listrindo?

\section{KAJIAN TEORI}

\subsection{Lingkungan Kerja}

Lingkungan kerja merupakan kehidupan sosial, psikologi, dan fisik dalam suatu perusahaan atau dalam suatu organisasi yang memiliki pengaruh terhadap setiap pekerja untuk dapat melakukan tugasnya. Kehidupan yang dijalani manusia tentu saja selalu tepengaruh terhadap keadaan lingkungan sekitarnya, antara manusia dan lingkungan memiliki hubungan yang erat dan tidak terpisahkan. Oleh karena itu manusia akan selalu mengusahakan untuk bisa membiasakan diri dengan keadaan lingkungan disekitarnya. Sama hal dengan ketika melakukan sebuah pekerjaan, karyawan sebagai manusia tidak bisa dipisahkan dengan keadaan tempat mereka bekerja, yaitu lingkungan kerja. Selama melakukan pekerjaan, setiap pegawai akan melakukan interaksi dengan sesama karyawan atau dengan kondisi yang ada didalam lingkungan kerja. Menurut Niti Semo (2013:159) mengatakan bahwa: "Lingkungan kerja adalah segala sesuatu yang ada disekitar para pekerja yang dapat mempengaruhi dirinya dalam menjalankan tugas-tugas yang diembankan”. 
Menurut Sedarmayati (2016:25) mengatakan bahwa: "Lingkungan kerja adalah suatu kondisi atau keadaan yang disekitar lingkungan tempat bekerja yang dapat mempengaruhi kinerja seseorang dalam melaksanakan tugas-tugasnya baik secara langsung maupun tidak langsung dan mempengaruhi optimalisasi hasil yang diperoleh dalam berpengaruh juga terhadap produktivitas perusahaan secara umum".

\subsection{Stress Kerja}

Pengertian Stress Kerja sebuah perasaan tertekan yang dialami karyawan pada saat menghadapi sebuah pekerjaan yang akan dikerjakan. Stress kerja ini tampak dari tampilan diri, antara lain emosi tidak stabil, perasaan tidak tenang, suka menyendiri, sulit tidur, merokok yang ber- lebihan, tidak bisa relaks, cemas, tegang, gugup, tekanan darah meningkat, dan mengalami gangguan pencernaan. Menurut Ivancevich dan Matterson (H. Suwatno dan Donni Juni Priansa 2016:255) dalam buku Manajemen SDM dalam Organisasi Publik dan Bisnis, mengatakan bahwa: "Stress merupakan respons adaptif, ditengahi oleh perbedaan individu yang merupakan suatu konsekuensi dari tindakan, situasi atau kejadian eksternal (lingkungan) yang menempatkan tuntutan fisik dan psikologis yang berlebihan terhadap seseorang".

Menurut Irham Fahmi (2016:214) mengatakan bahwa: "Stress adalah suatu keadaan yang menekankan diri dan jiwa seseorang diluar batas kemampuannya, sehingga jika terus dibiarkan tanpa ada solusi makan ini akan berdampak pada kesehatannya. Stress tidak timbul begitu saja namun sebab-sebab stress timbul umumnya diikuti oleh faktor peristiwa yang mempengaruhi kejiwaan seseorang, dan peristiwa yang mempengaruhi kejiwaan seseorang dan peristiwa itu terjadi di luar kemampuannya sehingga kondisi tersebut telah menekan jiwanya. Salah satu kondisi timbulnya stress disebabkan ketika seseorang melakukan sesuatu yang tidak sesuai dengan hati nuraninya namun hati nuraninya tidak sanggup untuk menolaknya, sehingga disini timbul pertentangan diri yang kuat atau kontra dengan batinnya".

Menurut Soesmalijah Soewondo (H. Suwatno dan Donni Juni Priansa 2016:255) dalam buku Manajemen SDM dalam Organisasi Publik dan Bisnis, mengatakan bahwa: "Stress kerja adalah suatu kondisi di mana terdapat satu atau beberapa faktor di tempat kerja yang berinteraksi dengan pekerja sehingga mengganggu kondisi fisiologis dan perilaku".

\subsection{Konflik}

Konflik bisa diartikan sebagai bertengkar, bersaing, atau memperebutkan. Konflik adalah sebuah ketidaksepakatan. Konflik juga suatu pertentangan yang seringkali terjadi dan diharapkan oleh seorang terhadap dirinya sendiri, orang lain, dan organisasi yang kenyataan diharapkannya.

Konflik adalah suatu proses yang seringkali muncul dalam kehidupan seseorang. Apabila tidak segera diselesaikan, konflik akan berkembang semakin besar dan membahayakan organisasi. Konflik merupakan suatu hubungan yang terjadi pada setiap manusia selama dia melakukan suatu hubungan. Menurut Sedarmayanti (2015:255) mengatakan bahwa: "Konflik adalah segala macam bentuk pertentangan antagonistic antara dua pihak atau lebih".

Menurut Irham Fahmi (2016:265) mengatakan bahwa: "Konflik adalah sebuah persepsi yang berbeda dalam melihat suatu situasi dan kondisi yang selanjutnya teraplikasi dalam bentuk aksi-aksi sehingga telah menimbulkan pertentangan dengan pihak-pihak tertentu". 
Menurut Wibowo (2016:25) mengatakan bahwa: "Konflik adalah hasil interaksi dimana pihak pertama merasa bahwa kepentingannya di tentang atau dipengaruhi secara negative oleh pihak lainnya".

\subsection{Kinerja}

Kinerja dalam bahasa inggris berarti adalah job performance atau actual performance. Yang kita simpulkan merupakan prestasi kerja atau prestasi yang harus dicapai oleh seseorang. Pengertian kinerja atau prestasi kerja adalah hasil kerja secara kualitas dan kuantitas yang dicapai oleh seorang pegawai dalam melaksanakan fungsinya sesuai dengan tanggung jawab yang diberikan kepadanya. Menurut Supriyadi (2015:194) mengatakan bahwa: "Kinerja adalah hasil kerja yang dapat dicapai seseorang atau sekelompok orang dalam suatu organisasi dalam rangka mencapai tujuan organisasi dalam periode waktu tertentu." Menurut Wirawan (2015:731) mengatakan bahwa: "Kinerja adalah salah satu variabel dependen yang berhubunhan langsung dengan kepemimpinan atau melalui variabel antara atau mediasi." Menurut Sedarmayanti (2017:463) mengatakan bahwa: "Kinerja adalah hasil kerja yang dicapai oleh seseorang/kelompok orang dalam suatu organisasi sesuai dengan wewenang dan tanggung jawab masing-masing dalam rangka mencapai tujuan organisasi yang bersangkutan."

\subsection{Hipotesis}

1. Diduga Lingkungan kerja $\left(\mathrm{X}_{1}\right)$ berpengaruh signifikan terhadap Kinerja (Y).

2. Diduga bahwa Stress kerja $\left(\mathrm{X}_{2}\right)$ berpengaruh signifikan terhadap Kinerja (Y).

3. Diduga konflik $\left(\mathrm{X}_{3}\right)$ berpengaruh signifikan terhadap kinerja $(\mathrm{Y})$

4. Diduga bahwa Lingkungan kerja $\left(\mathrm{X}_{1}\right)$, stress kerja, $\left(\mathrm{X}_{2}\right)$ dan konflik $\left(\mathrm{X}_{3}\right)$ berpengaruh signifikan terhadap Kinerja (Y).

\section{HASIL DAN PEMBAHASAN}

Pada Penelitian ini penulis mengambil PENGARUH LINGKUNGAN KERJA, STRESS KERJA DAN KONFLIK KERJA TERHADAP KINERJA KARYAWAN PADA PT TRUNOJOYO SUMBER LISTRINDO”.

Dan responden untuk dijadikan sampel dalam menjawab pernyataan-pernyataan yang diajukan penulid mengenai Pengaruh Lingkungan Kerja, Stress Kerja Dan Konflik Kerja Terhadap Kinerja Karyawan Pada PT. Trunojoyo Sumber Listrindo. dalam bentuk beberapa pernyataan atau kuensioner yang diajukan kepada 100 Karyawan PT. Trunojoyo Sumber Listrindo.

\subsection{PEMBAHASAN PENELITIAN}

\section{A. Uji Validitas dan Reliabilitas}

Pada penelitian ini penulis mengambil beberapa orang atau responden untuk dijadikan sampel dalam menjawab pernyataan-pernyataan yang diajukan penulis mengenai analisis Pengaruh Lingkungan Kerja, Stress Kerja Dan Konflik Kerja Terhadap Kinerja Karyawan Pada PT. Trunojoyo Sumber Listrindo dalam bentuk beberapa pernyataan atau kuisioner yang diajukan kepada 100 karyawan rang atau responden.

\section{1) Uji Validitas}

Pengujian validitas tiap butir pertanyaan dalam penelitian ini dilakukan dengan mengkorelasikan skor tiap butir dengan skor total. Untuk menguji apakah masingmasing indicator valid atau tidak, dengan membandingkan $r$ hitung dengan hasil 
perhitungan $r_{\text {tabel }}$ Karena $r$ hitung $>r_{\text {tabel }}$ dan bernilai positif maka indikator dinyatakan valid.

Tabel 2. Hasil Uji Validitas Kuesioner

\begin{tabular}{|c|c|c|c|c|}
\hline Variabel & $\mathrm{r}_{\text {hitung }}$ & $\mathrm{r}_{\text {tabel }}$ & Perbandingan & Keterangan \\
\hline \multicolumn{5}{|c|}{$\begin{array}{l}\text { Lingkungan Kerja } \\
\qquad\left(\mathrm{X}_{1}\right)\end{array}$} \\
\hline$X_{1}-1$ & 0.687 & 0,1966 & $\mathrm{r}_{\text {hitung }}>\mathrm{r}_{\text {tabel }}$ & Valid \\
\hline $\mathrm{X}_{1}-2$ & 0.781 & 0,1966 & $\mathrm{r}_{\text {hitung }}>\mathrm{r}_{\text {tabel }}$ & Valid \\
\hline$X_{1-3}$ & 0.734 & 0,1966 & $\mathrm{r}_{\text {hitung }}>\mathrm{r}_{\text {tabel }}$ & Valid \\
\hline$X_{1}-4$ & 0.716 & 0,1966 & $\mathrm{r}_{\text {hitung }}>\mathrm{r}_{\text {tabel }}$ & Valid \\
\hline$X_{1}-5$ & 0.699 & 0,1966 & $\mathrm{r}_{\text {hitung }}>\mathrm{r}_{\text {tabel }}$ & Valid \\
\hline$X_{1}-6$ & 0.784 & 0,1966 & $r_{\text {hitung }}>r_{\text {tabel }}$ & Valid \\
\hline$X_{1}-7$ & 0.768 & 0,1966 & $\mathrm{r}_{\text {hitung }}>\mathrm{r}_{\text {tabel }}$ & Valid \\
\hline$X_{1}-8$ & 0.700 & 0,1966 & $\mathrm{r}_{\text {hitung }}>\mathrm{r}_{\text {tabel }}$ & Valid \\
\hline$X_{1}-9$ & 0.792 & 0,1966 & $\mathrm{r}_{\text {hitung }}>\mathrm{r}_{\text {tabel }}$ & Valid \\
\hline \multicolumn{5}{|c|}{ Stress Kerja $\left(\mathbf{X}_{2}\right)$} \\
\hline $\mathrm{X}_{2}-1$ & 0.696 & 0,1966 & $\mathrm{r}_{\text {hitung }}>\mathrm{r}_{\text {tabel }}$ & Valid \\
\hline$X_{2}-2$ & 0.528 & 0,1966 & $\mathrm{r}_{\text {hitung }}>\mathrm{r}_{\text {tabel }}$ & Valid \\
\hline$X_{2-3}$ & 0.638 & 0,1966 & $\mathrm{r}_{\text {hitung }}>\mathrm{r}_{\text {tabel }}$ & Valid \\
\hline $\mathrm{X}_{2}-4$ & 0.605 & 0,1966 & $r_{\text {hitung }}>r_{\text {tabel }}$ & Valid \\
\hline$X_{2}-5$ & 0.780 & 0,1966 & $\mathrm{r}_{\text {hitung }}>\mathrm{r}_{\text {tabel }}$ & Valid \\
\hline$X_{2}-6$ & 0.637 & 0,1966 & $\mathrm{r}_{\text {hitung }}>\mathrm{r}_{\text {tabel }}$ & Valid \\
\hline $\mathrm{X}_{2}-7$ & 0.711 & 0,1966 & $\mathrm{r}$ hitung $>\mathrm{r}_{\text {tabel }}$ & Valid \\
\hline
\end{tabular}




\begin{tabular}{|c|c|c|c|c|}
\hline $\mathrm{X}_{2-8}$ & 0.606 & 0,1966 & $\mathrm{r}_{\text {hitung }}>\mathrm{r}_{\text {tabel }}$ & Valid \\
\hline $\mathrm{X}_{2-9}$ & 0.523 & 0,1966 & $\mathrm{r}_{\text {hitung }}>\mathrm{r}_{\text {tabel }}$ & Valid \\
\hline \multicolumn{5}{|c|}{ Konflik Kerja $\left(\mathbf{X}_{3}\right)$} \\
\hline $\mathrm{X}_{3-1}$ & 0.791 & 0,1966 & $\mathrm{r}_{\text {hitung }}>\mathrm{r}_{\text {tabel }}$ & Valid \\
\hline $\mathrm{X}_{3-2}$ & 0.895 & 0,1966 & $\mathrm{r}_{\text {hitung }}>\mathrm{r}_{\text {tabel }}$ & Valid \\
\hline $\mathrm{X}_{3-3}$ & 0.827 & 0,1966 & $\mathrm{r}_{\text {hitung }}>\mathrm{r}_{\text {tabel }}$ & Valid \\
\hline $\mathrm{X}_{3}-4$ & 0.749 & 0,1966 & $r_{\text {hitung }}>r_{\text {tabel }}$ & Valid \\
\hline $\mathrm{X}_{3-5}$ & 0.766 & 0,1966 & $\mathrm{r}_{\text {hitung }}>\mathrm{r}_{\text {tabel }}$ & Valid \\
\hline $\mathrm{X}_{3}-6$ & 0.596 & 0,1966 & $\mathrm{r}_{\text {hitung }}>\mathrm{r}_{\text {tabel }}$ & Valid \\
\hline $\mathrm{X}_{3-7}$ & 0.689 & 0,1966 & $r_{\text {hitung }}>r_{\text {tabel }}$ & Valid \\
\hline $\mathrm{X}_{3}-8$ & 0.569 & 0,1966 & $r_{\text {hitung }}>r_{\text {tabel }}$ & Valid \\
\hline $\mathrm{X}_{3-9}$ & 0.587 & 0,1966 & $r_{\text {hitung }}>r_{\text {tabel }}$ & Valid \\
\hline \multicolumn{5}{|c|}{ Kinerja $\mathbf{Y}$} \\
\hline Y-1 & 0.848 & 0,1966 & $\mathrm{r}_{\text {hitung }}>\mathrm{r}_{\text {tabel }}$ & Valid \\
\hline $\mathrm{Y}-2$ & 0.851 & 0,1966 & $\mathrm{r}_{\text {hitung }}>\mathrm{r}_{\text {tabel }}$ & Valid \\
\hline $\mathrm{Y}-3$ & 0.441 & 0,1966 & $\mathrm{r}_{\text {hitung }}>\mathrm{r}_{\text {tabel }}$ & Valid \\
\hline $\mathrm{Y}-4$ & 0.661 & 0,1966 & $r_{\text {hitung }}>r_{\text {tabel }}$ & Valid \\
\hline $\mathrm{Y}-5$ & 0.701 & 0,1966 & $\mathrm{r}_{\text {hitung }}>\mathrm{r}_{\text {tabel }}$ & Valid \\
\hline Y -6 & 0.426 & 0,1966 & $\mathrm{r}_{\text {hitung }}>\mathrm{r}_{\text {tabel }}$ & Valid \\
\hline Y -7 & 0.618 & 0,1966 & $\mathrm{r}_{\text {hitung }}>\mathrm{r}_{\text {tabel }}$ & Valid \\
\hline $\mathrm{Y}-8$ & 0.408 & 0,1966 & $\mathrm{r}_{\text {hitung }}>\mathrm{r}_{\text {tabel }}$ & Valid \\
\hline Y -9 & 0.365 & 0,1966 & $r_{\text {hitung }}>r_{\text {tabel }}$ & Valid \\
\hline Y -10 & 0.621 & 0,1966 & $\mathrm{r}_{\text {hitung }}>\mathrm{r}_{\text {tabel }}$ & Valid \\
\hline Y -11 & 0.597 & 0,1966 & $r_{\text {hitung }}>r_{\text {tabel }}$ & Valid \\
\hline
\end{tabular}




\begin{tabular}{|l|l|l|l|l|}
\hline $\mathrm{Y}-12$ & 0.538 & 0,1966 & $\mathrm{r}_{\text {hitung }}>\mathrm{r}_{\text {tabel }}$ & Valid \\
\hline
\end{tabular}

Dari tabel 2 diatas, di mana semua nilai $\mathrm{r}$ hitung dari item-item pertanyaan dalam kuesioner lebih besar dari nilai $r_{\text {tabel }}$ artinya semua item pertanyaan baik lingkungan kerja $\left(\mathrm{X}_{1}\right)$, Stress kerja $\left(\mathrm{X}_{2}\right)$, konflik kerja $\left(\mathrm{X}_{3}\right)$, dan kinerja karyawan $(\mathrm{Y})$ valid

\section{2) Uji Reabilitas}

Uji Reabilitas dilakukan untuk menilai konsisten dari instrument penelitian. Suatu instrument variabel penelitian dikatakan realibel jika Nilai Cronbach's Alpha lebih besar dari standar pengujian $(\alpha) 0,70$

Tabel 3. Hasil Uji reliabilitas kuesioner

\begin{tabular}{|l|l|c|c|}
\hline \multicolumn{1}{|c|}{ Variabel } & Nilai Cronbach's Alpha & Standar Pengujian $(\alpha)$ & Keterangan \\
\hline Lingkungan Kerja $\left(\mathrm{X}_{1}\right)$ & 0.928 & 0,70 & Reliabel \\
\hline Stress Kerja $\left(\mathrm{X}_{2}\right)$ & 0.885 & 0,70 & Reliabel \\
\hline Konflik Kerja $\left(\mathrm{X}_{3}\right)$ & 0.919 & 0,70 & Reliabel \\
\hline Kinerja (Y) & 0.886 & 0,70 & Reliabel \\
\hline
\end{tabular}

Dari tabel 3 terlihat bahwa semua variabel dalam penelitian ini sudah reliable, hal ini terlihat dari nilai cronbach's alpha untuk variabel Lingkungan Kerja (X1), Stress kerja (X2), Konflik kerja (X3), dan kinerja (Y) lebih besar (>) 0,70

3) Uji Koefisien Determinasi $\left(\mathbf{R}^{2}\right)$

Koefisien determinasi (R2) digunakan untuk mengukur seberapa jauh kemampuan model dalam menerapkan variasi dependen (Kinerja karyawan). Pengujian Goodness of Fit dari model regresi yang nilai adjusted R2 dapat dilihat dari tabel 6 sebagai berikut:

Tabel 6. Model Summaryb

\begin{tabular}{|c|c|c|c|c|c|c|c|c|c|}
\hline \multirow[b]{2}{*}{ Model } & \multirow[b]{2}{*}{$\mathrm{R}$} & \multirow[b]{2}{*}{ R Square } & \multirow[b]{2}{*}{$\begin{array}{l}\text { Adjusted R } \\
\text { Square }\end{array}$} & \multirow[b]{2}{*}{$\begin{array}{c}\text { Std. Error of the } \\
\text { Estimate }\end{array}$} & \multicolumn{5}{|c|}{ Change Statistics } \\
\hline & & & & & \begin{tabular}{c|} 
R Square \\
Change
\end{tabular} & F Change & df1 & df2 & $\begin{array}{c}\text { Sig. F } \\
\text { Change }\end{array}$ \\
\hline 1 & $.935^{\mathrm{a}}$ & .874 & .870 & 2.967 & .874 & 221.640 & 3 & 96 & .000 \\
\hline
\end{tabular}

a. Predictors: (Constant), Lingkungan Kerja, Stress Kerja, Konflik

Kerja

b. Dependent Variable: Kinerja Karyawan

Sumber: SPSS 20.00

Berdasarkan hasil perhitungan dengan SPSS for window nilai adjusted R2 dalam penelitian ini sebesar $80.7 \%$ lingkungan kerja, stress kerja, dan konflik kerja memberikan sumbangan sebesar $80.7 \%$ terhadap Kinerja Karyawan pada. PT. Trunojoyo Sumber Listrindo sementara 19,3\% dijelaskan oleh sebab-sebab yang lain. 
4) Uji Signifikan simultan (uji F)

Uji stastistik F pada dasarnya menunjukkan apakah semua variabel independen yang dimasukkan dalm model mempunyai pengaruh secara bersama-sama terhadap variabel dependen. Hasil uji simultan (Uji F) dalam penelitian ini dapat dilihat pada tabel 7 sebagai berikut:

Tabel 7. ANOVA

\begin{tabular}{|c|c|c|c|c|c|c|}
\hline \multicolumn{2}{|c|}{ Model } & Sum of Squares & $\mathrm{Df}$ & Mean Square & $\mathrm{F}$ & Sig. \\
\hline \multirow[t]{3}{*}{1} & Regression & 5853.169 & 3 & 1951.056 & 221.640 & $.000^{\mathrm{a}}$ \\
\hline & Residual & 845.071 & 96 & 8.803 & & \\
\hline & Total & 6698.240 & 99 & & & \\
\hline
\end{tabular}

a. Predictors: (Constant), Lingkungan Kerja, Stress Kerja, Konflik Kerja

Dari hasil uji $F$ diperoleh hasil untuk Nilai $F$ hitung sebesar 221.640 dengan nilai signifikansi sebesar 0.000 sehingga nilai $\mathrm{F}$ hitung $>\mathrm{F}$ tabel atau $221.640>3.09$ atau tingkat signifikasi (sig) $0.000<0.05$, sehingga keputusannya menolak Ho dan menerima Ha. Hal ini berarti secara simultan (bersama-sama) variabel bebas (lingkungan kerja, stress kerja dan konflik kerja) mempengaruhi terhadap Kinerja Karyawan pada PT. Trunojoyo Sumber Listrindo.

5) Uji parsial (uji t)

Uji stastitik t pada dasarnya menunjukkan seberapa jauh pengaruh variabel independen secara individu dalam menerangkan varaibel dependen

Tabel 5. Uji T

Coefficients $^{\mathrm{a}}$

\begin{tabular}{|c|c|c|c|c|c|c|c|c|}
\hline \multirow{2}{*}{\multicolumn{2}{|c|}{ Model }} & \multicolumn{2}{|c|}{$\begin{array}{c}\text { Unstandardized } \\
\text { Coefficients }\end{array}$} & \multirow{2}{*}{$\begin{array}{c}\begin{array}{c}\text { Standardized } \\
\text { Coefficients }\end{array} \\
\text { Beta }\end{array}$} & \multirow[b]{2}{*}{$t$} & \multirow[b]{2}{*}{ Sig. } & \multicolumn{2}{|c|}{$\begin{array}{c}\text { Collinearity } \\
\text { Statistics }\end{array}$} \\
\hline & & $B$ & Std. Error & & & & Tolerance & VIF \\
\hline \multirow[t]{4}{*}{1} & (Constant) & 1.855 & 1.614 & & 1.149 & .253 & & \\
\hline & Lingkungan Kerja & .694 & .094 & .457 & 7.420 & .000 & .346 & 2.887 \\
\hline & Stress Kerja & .610 & .092 & .408 & 6.604 & .000 & .344 & 2.907 \\
\hline & Konflik Kerja & .231 & .061 & .172 & 3.778 & .000 & .632 & 1.582 \\
\hline
\end{tabular}

a. Dependent Variable:

Kinerja 
Berdasarkan tabel analisis data uji parsial Variabel konflik kerja secara parsial, nilai t hitung lingkungan kerja $7.420>$ ttabel 1,966 dan $.0 .000<0.05$ sehingga hipotesis nol (Ho) ditolak dan hipotesis alterntif (Ha) diterima, hal ini menunjukan variabel lingkungan kerja berpengaruh secara signifikan terhadap Kinerja Karyawan pada. PT Trunojoyo Sumber Listrindo, variabel stress kerja secara parsial nilai t hitung stress kerja 6.604. $>$ ttabel 1,966 dan $.0 .000<0.05$, sehingga hipotesis nol (Ho) ditolak dan hipotesis alterntif (Ha) diterima, hal ini menunjukan variabel stress kerja berpengaruh secara signifikan terhadap Kinerja Karyawan pada PT. Trunojoyo Sumber Listrindo dan variabel konflik kerja secara parsial nilai $t$ hitung konflik kerja $3.778>t_{\text {tabel }} 1,966$ dan $.0 .000<0.05$, sehingga hipotesis nol (Ho) ditolak dan hipotesis alterntif $(\mathrm{Ha})$ diterima, hal ini menunjukan variabel konflik kerja berpengaruh secara signifikan terhadap Kinerja Karyawan pada PT.Trunojoyo Sumber Listrindo.

\section{KESIMPULAN}

1. Uji Validitas maupun uji realibilitas menunjukkan bahwa semua item pertanyaan dari variabel lingkungan kerja $\left(\mathrm{X}_{1}\right)$, stress kerja $\left(\mathrm{X}_{2}\right)$, dan konflik kerja $\left(\mathrm{X}_{4}\right)$ semua pertanyaan yang diajukan kepada responden adalah valid dan reliable.

2. Berdasarkan hasil uji t menunjukkan bahwa besarnya $t$ nilai $t$ hitung untuk lingkungan kerja adalah 7.420, nilai $t$ hitung untuk stress kerja sebesar 6.604, dan nilai $t$ hitung untuk konflik kerja sebesar 3.778 yang semuanya menunjukkan lebih besar dari t tabel 1.966, sehingga hipotesis ini menyatakan bahwa lingkungan kerja, stress kerja, dan konflik kerja berpengaruh positif secara parsial terhadap Kinerja Karyawan pada PT.Trunojoyo Sumber Listrindo (Y)

3. Berdasarkan hasil uji $F$ menunjukkan bahwa $F$ hitung (221.640) $>F$ tabel (3.09), sehingga variabel lingkungan kerja, stress kerja dan konflik kerja secara bersama-sama berpengaruh terhadap kinerja karyawan pada PT.Trunojoyo Sumber Listrindo (Y)

4. Nilai $t$ hitung lingkungan kerja adalah paling besar dibandingkan dengan variabel independen lainnya, sehingga variabel ini merupakan variabel yang paling dominan pengaruhnya terhadap Stress Kerja Karyawan pada PT.Trunojoyo Sumber Listrindo (Y)

5. Berdasarkan hasil koefisien determinasi menunjukkan bahwa lingkungan kerja, stress kerja dan konflik kerja memberikan sumbangan sebesar $80.7 \%$ terhadap kinerja Karyawan pada PT.Trunojoyo Sumber Listrindo (Y).

\section{SARAN}

a. Diharapkan PT. Trunojoyo Sumber Listrindo mampu terus mengevaluasi dan menyesuaikan lingkungan kerja, stres kerja, dan konflik kerja agar kinerja karyawan terus meningkat supaya PT. Trunojoyo Sumber Listrindo dapat terus maju dan berkembang.

b. Ada baiknya PT. Trunojoyo Sumber Listrindo memberikan program-program yang mempererat hubungan antar sesame karyawan dan juga kepada atasan agar terjalin hubungan dan menciptakan lingkungan kerja yang baik bagi perusahaan, sehingga selain mempercepat mencapai tujuan perusahaan tentunya juga akan meningkatkan kinerja karyawan. 


\section{DAFTAR PUSTAKA}

Amiro, T., \& Yonata, H. (2019). Peranan Orang Tua dalam Meningkatkan Kecerdasan Spiritual Anak menurut Perspektif Buddhis. Jurnal Ilmu Agama dan Pendidikan Agama Buddha, $1(1), 29-44$.

Alex, S, Niti Semo. "Manajemen Personalia (Manajemen Sumber Daya Manusia)”. Jakarta: GhaliaIndonesia, 2013

Badrudin. "Dasar - Dasar Manajemen”. Bandung: Alfabeta, 2014

Cahyono, Y., Purwanto, A., Sukanta, F. N. A., Fitriaty, H. W., Sihotang, M., \& Sugianto, A. (2020). Impact Of Service Quality, University Image And Students Satisfaction Towards Student loyalty: Evidence From Indonesian Private Universities. Journal of Critical Reviews, 7(19), 3916-3924.

E. B., Subakti. “Manajemen Perusahaan”. Jakarta: Pranata, 2012

Fahmi, Irham. "Manajemen Sumber Daya Manusia”. Bandung: Alfabeta 2016

Feriyanto, Andri dan Endang Shyta Triana. "Pengantar Manajemen (3IN1)”. Kebumen: Mediatera, 2015

Haudi, H. W., \& Cahyono, Y. (2020). Effect Of Product Innovation and Marketing Strategy on Consumer Purchase Decisions In Indonesia's Lightweight Roof Steel Industry. Journal of Critical Reviews, 7(13), 4147-4155.

Haudi, H. W., \& Cahyono, Y. (2020). Analysis of Most Influential Factors to Attract Foreign Direct Investment. Journal of Critical Reviews, 7(13), 4128-4135.

Kusuma, G., Yonata, H., \& Handoko, A. L. (2020). Peranan Kebudayaan Tionghoa terhadap Perkembangan Agama Buddha: Studi Kasus di Desa Rancaiyuh Kecamatan Panongan Kabupaten Tangerang. Jurnal Ilmu Agama dan Pendidikan Agama Buddha, 2(2), 117-130.

Lubis, A. "Lingkungan Kerja Yang Kondusif Dan Faktor-Faktor Yang Mempengaruhinya", IAIN Padangsidimpuan Vol 3, hal. 1-18

M.Manullang. "Dasar - Dasar Manajemen”. Yogyakarta: Gadjah Mada University Press, 2015

Mayasari, L. I., Butarbutar, M. H., Simorangkir, J., \& Yonata, H. (2020). WOMEN'S MARJINALIZATION IN SIRI AND EARLY MARINE CASE IN BUGIS MAKASSAR COMMUNITY BASED ON EDUCATION. PalArch's Journal of Archaeology of Egypt/Egyptology, 17(7), 13167-13183.

Norianggono, Hamid, \& Ruhana. "Pengaruh Lingkungan Kerja Fisik Dan Non Fisik Terhadap Kinerja Karyawan", Fakultas Ilmu Administrasi Universitas Brawijaya Vol. 8, Maret 2014, hal. 1-10 
Novitasari, E. “Manajemen Kantor Praktis", Bandung: Alfabeta, 2017

Priansa, Donni Juni. "Perencanaan dan Pengembangan Sumber Daya Manusia”. Bandung: Alfabeta 2016

Rahman, M. "Ilmu Administrasi”. Makassar: CV Sah Media, 2017

Sedarmayanti. "Manajemen Sumber Daya Manusia Reformasi Birokrasi Manajemen Pegawai Negeri Sipil”. Bandung: Rafika Aditama, 2016

Sedarmayanti. "Perencanaan dan Pengembangan Sumber Daya Manusia". Bandung: Refika Aditama, 2017

Setyawati, E., Widjayanti, C., Siraiz, R., \& Wijoyo, H. (2021). Pengujian keamanan komputer kriptografi pada surat elektronik berbasis website dengan enkripsi metode MD5. Jurnal Manajamen Informatika Jayakarta, 1(1), 56-67. Retrieved from http://journal.stmikjayakarta.ac.id/index.php/JMIJayakarta/article/view/367

Sidanti. "Pengaruh Lingkungan Kerja, Disiplin Kerja, Dan Motivasi Kerja Terhadap Kinerja Pegawai Negeri Sipil Di Seketariat DPRD Kabupaten Madiun”. Program Studi STIE Dharma Iswara MadiunVol. 9, hal. 1-13

Sinambela, Lijan Poltak. "Manajemen Sumber Daya Manusia”. Jakarta: Bumi Aksara, 2016

Sugandha, S. (2019). Pengaruh Lingkungan Kerja Dan Stress Kerja Terhadap Kinerja Karyawan (Studi Kasus di PT. KEONG NUSANTARA ABADI). Primanomics: Jurnal Ekonomi \& Bisnis, 17(2), 38-47.

Sugandha, S., Wibowo, F. P., \& Hendra, H. (2019). PENGARUH PELATIHAN DAN PENGEMBANGAN SUMBER DAYA MANUSIA TERHADAP PRESTASI KERJA KARYAWAN PT. JEMBO ENERGINDO. Dynamic Management Journal, 3(2).

Sugandha, S. (2019). Pengaruh Lingkungan Kerja Dan Stress Kerja Terhadap Kinerja Karyawan (Studi Kasus di PT. KEONG NUSANTARA ABADI). Primanomics: Jurnal Ekonomi \& Bisnis, 17(2), 38-47.

Sunyoto, Danang. "Manajemen Sumberdaya Manusia". Yogyakarta; Center for academic publishing service (CAPS), 2012

Sugiyono. “Metode Penelitian Kuantitatif, Kualitatif, Dan R\&D”. Bandung: Alfabeta, 2017

Suparyadi. “Manajemen Sumber Daya Manusia”. Yogyakarta: Andi Publisher, 2015

Supomo, R. “Pengaruh Lingkungan Kerja Terhadap Perkembangan Perusahaan”, Jurnal Ekonomi Bisnis. Mei 2018, Hal 1-10

Suwatno, dan Donni Juni Priansa. "Manajemen Sumber Daya Manusia dalam Organisasi Publik dan Bisnis". Bandung: Alfabeta, 2016 
Torang, Syamsir. “Organisasi \& Manajemen”. Bandung: Alfabeta, 2013

Yonata, H., Setiawan, P., Santamoko, R., Ilham, D., \& Asdiany, D. (2020). Pengaruh Kualitas Pelayanan dan Kepuasan Konsumen terhadap Loyalitas Pelanggan pada PT. Satria Antaran Prima. Jurnal Ilmu Komputer dan Bisnis, 11(2), 2502-2514.

Yonata, H. Kepuasan Mahasiswa Program Studi Pendidikan Agama Buddha terhadap Pelayanan Teknologi dan Sistem Informasi Perguruan Tinggi Keagamaan Buddha di Tangerang.

Wibowo. “Manajemen Kinerja”. Jakarta: Rajawali Pers, 2015

Wibowo, F. P., Sugandha, S., \& Tholok, F. W. (2020). PENGARUH BUDAYA ORGANISASI DAN LINGKUNGAN KERJA TERHADAP KINERJA (Studi Kasus di PT Mutiara Nusantara Globalindo). JURNAL EKONOMI DAN KEWIRAUSAHAAN, 20(3).

Widiyanto, G., \& Sugandha, S. (2019). Analisis Pengaruh Marketing Mix Terhadap Keputusan Pembelian Produk Makanan Cepat Saji. Primanomics: Jurnal Ekonomi \& Bisnis, 17(1), 33-44.

Wijoyo, H. DETERMINANT OF CUSTOMER VALUE AND ITS IMPLICATION ON CUSTOMER SATISFACTION PRIVATE HOSPITAL IN RIAU PROVINCE.

Wijoyo, H. (2021). PERSEPSI MAHASISWA TENTANG APLIKASI CHATTING SIGNAL. Jurnal Teknologi Dan Sistem Informasi Bisnis, 3(1), 153-156.

Wijoyo, H., \& Sunarsi, D. (2020). Manajemen internasional. CV. Insan Cendekia Mandiri.

Wijoyo, H., Limakrisna, N., \& Suryanti, S. (2021). The effect of renewal privacy policy whatsapp to customer behavior. Insight Management Journal, 1(2), 26-31.

Wirawan. “Manajemen Sumber Daya Manusia”. Banjarmasin: Rajawali Pers, 2015 